\title{
Beauty Standards set by Social Media and their Influence on Women's Body Image
}

\author{
Fadi Yamout \\ The International University of Beirut \\ Beirut campus \\ fadi.yamout@liu.edu.lb
}

\author{
Jenny Issa \\ The International University of Beirut \\ Beirut campus \\ 51430705@students.liu.edu.lb
}

\author{
Alia Ghaddar \\ The International University of Beirut \\ Beirut campus \\ alia.ghaddar@liu.edu.Ib
}

\begin{abstract}
Digital devices became increasingly integrated into our daily life since society relies much on them for communication. Digital devices are mostly used for social media that has a positive benefit, such as contacting friends and sharing memories. Social media turned out to be the complete opposite of its purpose. It gradually progressed into setting beauty standards and has started to impact people's self-esteem, as well as their tendencies to depression, and anxiety because of body image dissatisfaction. The reason for that is that the brain treats information about oneself as a reward, and many people are sensitive to self-relevant information and social image. They consider this information as an assessment of their social rank and reputation. This research aims to investigate the influence of social media on the body image dissatisfaction among women in Lebanon and how it influences their self-confidence and decision-making. We also aim to check whether women in Lebanon are more prone to have addictive tendencies towards social networking sites and applications than males.
\end{abstract}

Beauty Standards. Social Media. Body Image.

\section{INTRODUCTION}

Social Media are utilized to ease communication and connection between people in the same country or around the world through digital devices; it has connected societies that are incredibly distinctive. It is increasing in popularity due to the dramatic rise in mobile phone ownership. With twothirds of the world's population now having a mobile phone - that is over five billion people (Garst, Kim, 2019). Social media has become so widespread and popular (O'Keeffe GS, 2011) (Liu $R-D, 2013$ ) that researchers have grown interested in investigating its effects. In this paper, we investigate how it influences the body image. The objective of this paper is to show that the primary use or purpose for using social media is sharing personal details, comments, image, video posts. This outcome demonstrates that most of the people tend to expose their photos to the public. We will back up this outcome by statistics from agencies and from a survey that we have conducted on Lebanese mostly female and single. Then will show that most of the teenage girls use social media and with references to studies in the development of traits in personalities we show how Teenage experiences influences adulthood to conclude that teenage girls will follow the beauty standards of the social media when they become adults by

\section{RESEACH CENTERS \& SATISTICS' TOOLS}

Due to the importance of statistical tools and research centres conducting public opinion polling, we have used many as reference in our paper. These are the Pew Research Centre that is a nonprofit organization that conducts public opinion polling, demographic research, content analysis and other data-driven social science research, the Nielson Social that is a leading seller of audiences with common interests based on a large number of occurrences found on the Internet, the IndexMundi that contains detailed country statistics, charts, and maps gather from multiple sources, the We Are Social that is a global agency that connects people and brands in meaningful ways and creates ideas people like and share, and finally the Crowd DNA that has offices in London, Amsterdam, New York, Singapore and Sydney and operates across 60+ markets.

\section{METHODOLOGY}

\subsection{Tree-like model}


The methodology used in this paper is to use a tree-like model of research questions and their possible outcomes (Santos $R, 2014$ ), to investigate if beauty standards set by social media influence teenager's body image (Figure 1).

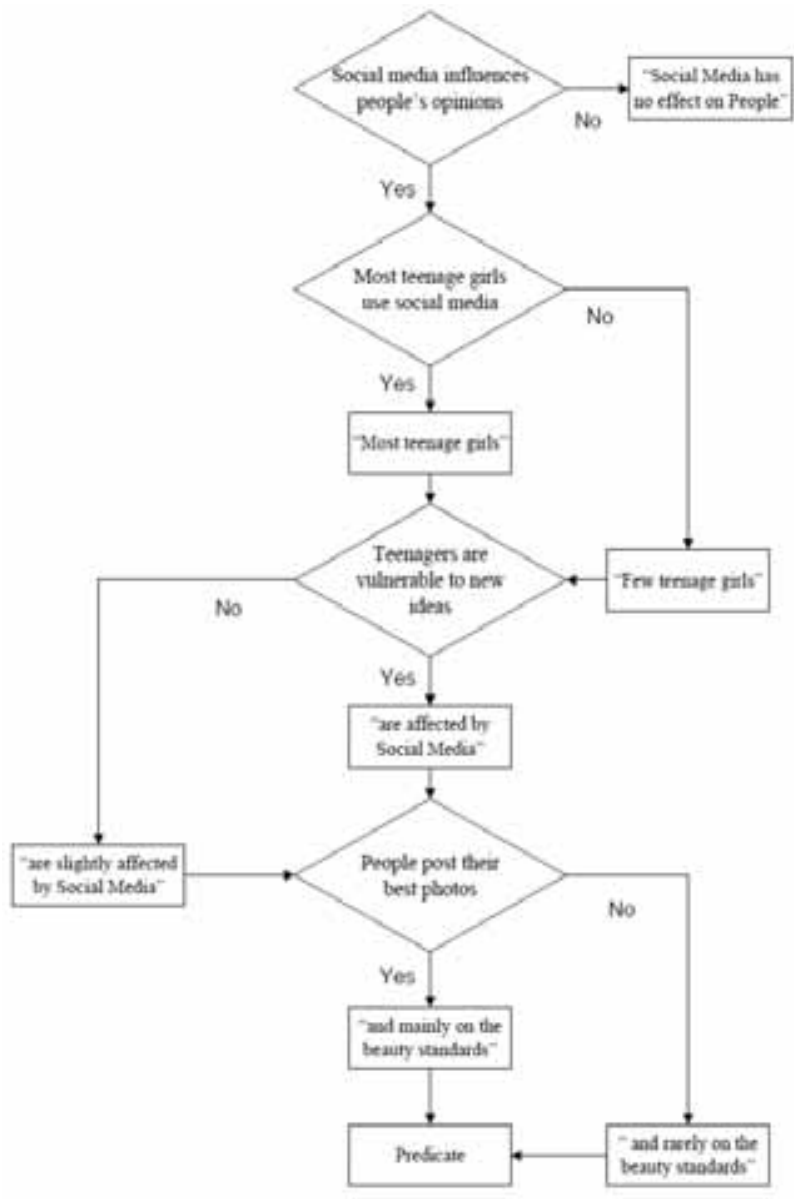

Figure 1: Tree-like model of questions and possible outcomes

After that, we examine if teenage experiences affect their adulthood. Combining the two findings, we can conclude whether or not beauty standards set by social media influence women's body image. The tree, shown in Figure 1, has for each internal node a research question and for each branch an outcome of the research question. The four research questions are:

- Social media influences people's opinions

- Most teenage girl uses social media

- Teenagers are vulnerable to new ideas

- People post their best photos

The outcomes are:

- Most teenage girls

- Few teenage girls

- $\quad$ are influenced by social media

- $\quad$ are slightly influenced by social media?

- Mainly on the beauty standards

- Rarely on the beauty standards
The possible outcomes derived from the root to the leaf are one of the possible predicates shown below:

- 1. Few teenage girls are slightly influenced by social media and rarely on the beauty standards

- 2. Few teenage girls are influenced by social media and rarely on the beauty standards

- 3. Few teenage girls are slightly influenced by social media and mainly on the beauty standards

- 4. Few teenage girls are influenced by Social Media and mainly on the beauty standards

- 5. Most teenage girls are slightly influenced by social media and rarely on the beauty standards

- 6. Most teenage girls are influenced by social media and rarely on the beauty standards

- 7. Most teenage girls are slightly influenced by social media and mainly on the beauty standards

- 8. Most teenage girls are influenced by social media and mainly on the beauty standards

Predicate number eight: " 8 . Most teenage girls are influenced by social media and mainly on the beauty standards ", is what we are aiming to prove. Then, we examine that childhood experiences influence adulthood to conclude that most women are influenced by social media and mainly on the beauty standards. The questions and their outcomes will be discussed in details in Chapter 4 to reach this prediction and support the hypothesis.

\subsection{Survey}

In order to collect data from respondents to gain more information and awareness related to this paper, we have built a survey using Google Form and it was sent to the users as a URL link to the online survey. The information was then collected and automatically connected to a spreadsheet and statistics were generated and included in this paper. The survey is composed of titles and subtitles, and in order for respondents to provide accurate feedback, we have added some explanations next to each sub-title.

The titles of the survey are:

- General Information

- Self-esteem and body satisfaction

- Sociocultural attitudes towards appearance

- The tendency for appearance comparison

- Social media exposure

- Social media addiction 
- Envy and stereotypes

- Social media has influence user's decisionmaking process

We have also created an Arabic version of the survey to make sure that most of the respondents' reply

\section{CHILD DEVELOPMENT}

This section describes the physical and psychological changes that children undergo from birth through adolescence and the transitional stage from childhood to adulthood.

\subsection{Child}

The rapid physical and psychological changes that children undergo from birth through adolescence often leave parents and caregivers wondering how best to engage and help them. The process of child development can include everything from sensory awareness and excellent motor skills to language and socialization ability. It is strongly influenced by a child's genetic makeup, environment, and cognitive skills. Parents and medical professionals frequently use developmental milestones, such as when a child learns to speak or read, to track that child's growth relative to their peers. These milestones can also help identify any learning disabilities or behavioural problems a child may have, so that they can be addressed early, but it is important to note that these are just benchmarks and may have no bearing on a child's ultimate capabilities.

\subsection{Teenager}

Teenage describes the years between ages 13 and 19 and can be considered the transitional stage from childhood to adulthood. However, the physical and psychological changes that occur in teenage can start earlier, during the preteen or "tween" years (ages 9 through 12). Teenage can be a time of both disorientation and discovery. This transitional period can bring up issues of independence and self-identity; many Teenagers and their peers face tough choices regarding school, sexuality, drugs and alcohol, and social life. Peer groups, romantic interests, and appearance tend to naturally increase in perceived importance for some time during a teen's journey toward adulthood

This chapter examines the research questions posed in chapter 3 and for each question identifies a possible outcome. The expected result is to demonstrate that "Most teenage girls are influenced by social media and mainly on the beauty standards". Then, we examine that childhood experiences influence adulthood to conclude that social media influence the lives of the girls and mainly on the beauty standards can influence their life when they become adults by following the beauty standards of the social media.

Lebanon has a significant Western influence evident in its society where media messages often emphasize a culture of "thinness" and "perfection" (Richa, 2019). For that reason, and in a very few cases, we consider statistics or studies done in western countries to an extent applicable to Lebanese culture.

\section{RESULTS}

The following sections examine each of the four research questions in details and identify the possible outcomes. The research questions are whether or not social media influences people, if most teenage girl uses social media, if teenagers are vulnerable to new ideas, and whether or not people post their best photos on social media.

\subsection{Social media influences people's opinions}

The effects of social media are both physical and mental (Zhukova, 2018). Spending too long on social networking sites affects the mood and more likely to report poor mental health, including symptoms of depression. Depression is not the cause of the only symptom by social media. Fear of Missing out (FOMO) is a form of anxiety the user gets when scared of missing out on a positive experience or emotions that someone else is getting (Zhukova, 2018). Therefore, the user will be continuously engaged in social media and more likely to see that someone is having more fun and that is precisely what causes FOMO. This is one cause of being addictive to social media, Addiction to social media were shown in many studies, in our survey, we found that more than $70 \%$ of the respondent check social media at least few times daily which is considered an addiction.

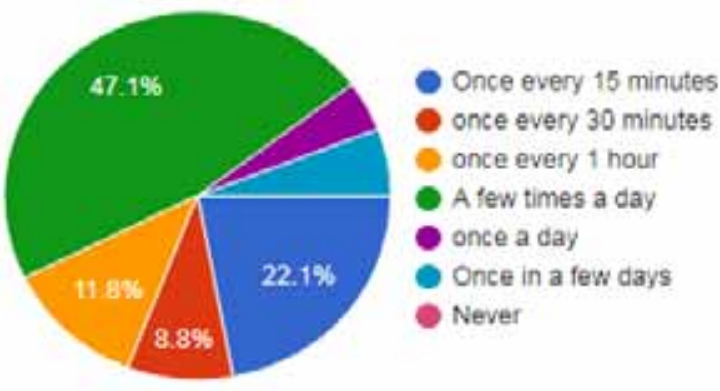

Figure 2: Frequent checking of social media

The mass media has a significant influence on people and especially on the younger generation. It plays an essential role in shaping the opinions and positions of young people (Zhukova, 2018). The young people are more isolated and do not know how to interact with society. They gradually lose their communications skills and the intimacy of 
face-to-face interactions (Dakin, 2014). According to (Harrington, 2013), teenagers are posting selfies on social networking to get more attention from others. Young girls are more likely to be dissatisfied with their shape and weight, even if they are very healthy and balanced from this (Sameer, 2014).

\subsection{Most teenage girls use social media}

To prove that most teenage girl in Lebanon uses social media, we have examined a few factors related to this hypothesis. First we define how many teenagers in Lebanon, and mainly teenage female, are Internet users. Then we examine how many of them use social media. Finally, we examine if girls use social media more than their male gender.

\subsubsection{The teenage girl as Internet users}

According to We Are Social, user's convenience and constant access provided by mobile devices, especially smartphones increased the number of users accessing the Internet (Garst, Kim, 2019). For that reason, over 4 billion people around the globe are now using the internet as shown in Figure 3 . Of these users, over 3 billion regularly use social media

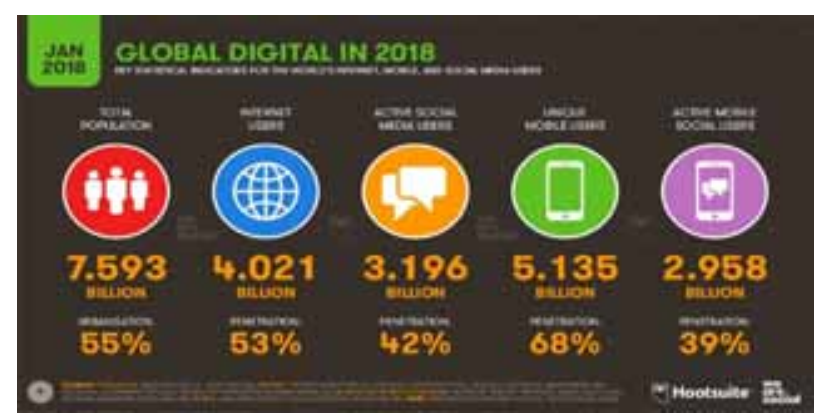

Figure 3: Distribution of Internet users in the world

Based on We Are Social1 and Hootsuite, Kemp has shown that $91 \%$ of the population in Lebanon are Internet users (Kemp, 2018) as shown in Figure 4:

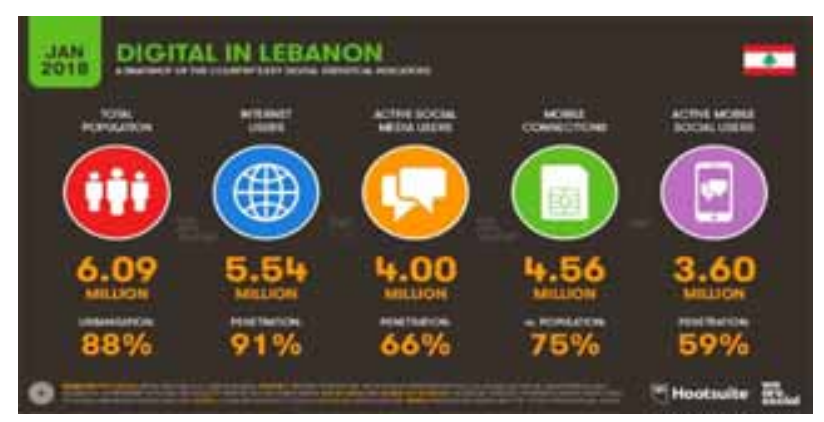

Figure 4: Distribution of Internet users in Lebanon

The remaining $9 \%$ of the population that counts around 550,000 people are non-user Internet It should be noted that infant (ages four weeks - 1 year); toddler (ages 1-3 years); and to some extent pre-schooler (ages 4-6 years) do not use the
Internet. Furthermore, and concerning the population pyramid in Lebanon hosted by the data portal indexMundi in Figure 5, we can deduce that the remaining $9 \%$, of the population that are nonuser Internet is mostly among this category.

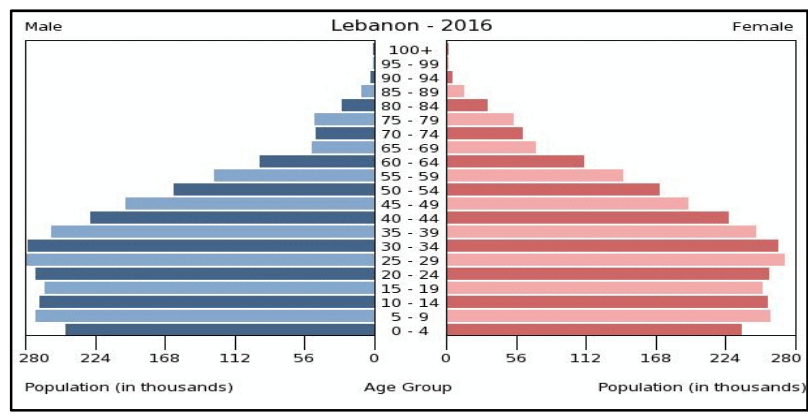

Figure 5: Population pyramid in Lebanon

As a result, almost all Lebanese people are Internet users except for the very young. Therefore, almost all teenagers in Lebanon are Internet users and consequently almost all female teenagers are Internet users.

\subsubsection{Teenage girls as social media users}

Next we examine how many of the Internet users are considered as active social media users. Figure 4 showed that $66 \%$ of the population is considered as active social media users (Kemp, 2018). Since we have shown in the previous section that almost all teenage females are Internet users, therefore, $66 \%$ of teenage females are active social media users. It should be noted here that this percentage is increasing significantly. Figure 6 shows that the number of active social media users increased by $14 \%$ from 2017 till 2018, therefore, the $66 \%$ of teenage females active on social media has become much higher this year and will be almost saturated next year.

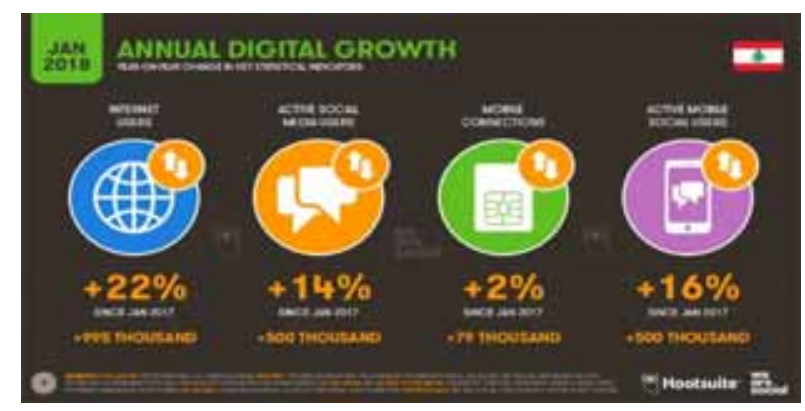

Figure 6: Annual digital growth in Lebanon

5.2.3. Girls use social media more than boys As evidence on how social media affects mental health and is stronger for girls than boys, a new study (Cara Booker, 2018) finds that girls used social media more than boys did, and their mental health seemed to suffer for it. Teenage girl uses social media sites for sharing more than their male colleagues do. As for the boys, they are more likely than girls to own gaming consoles and play video games as shown in Figure 7. 


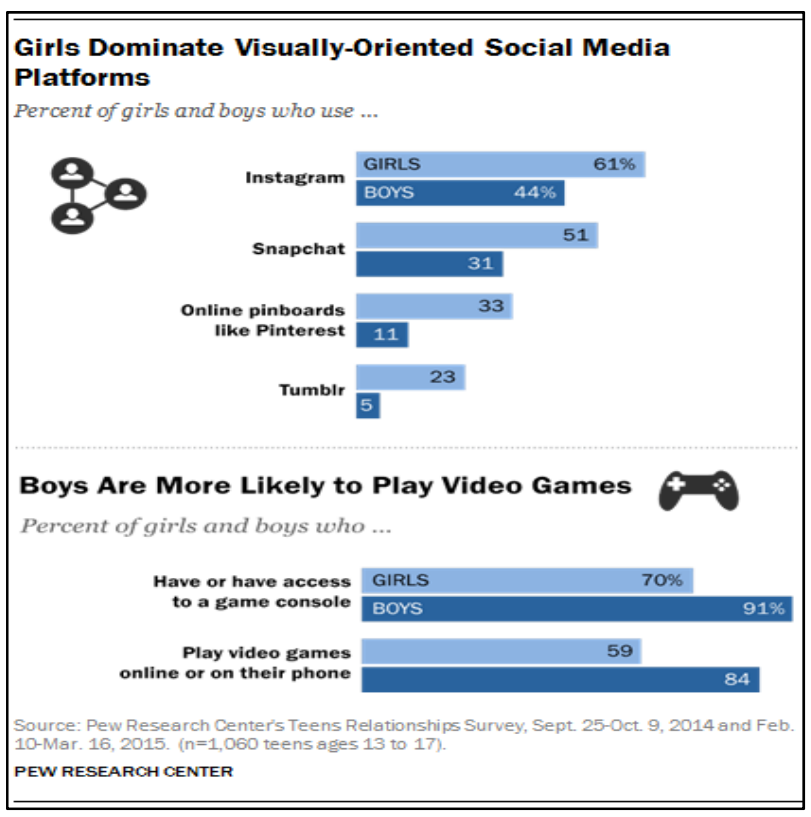

Figure 7: Girls vs. boys on Social Media

At age 10, girls reported lower levels of happiness, and they reported more social and emotional difficulties compared to boys. The authors of the new study suggest that girls may be more likely to make comparisons between themselves and others -and earlier research has shown that it is the comparison-making, in either direction, that seems to be a root cause of social media's harmful effects. (Mai-Ly Steers, 2014). In the survey we have conducted on 100 users, most of them females and single, we found that more than $85 \%$ of the users (Figure 8) think that women in Lebanon are more prone to have addictive tendencies towards social media than males.

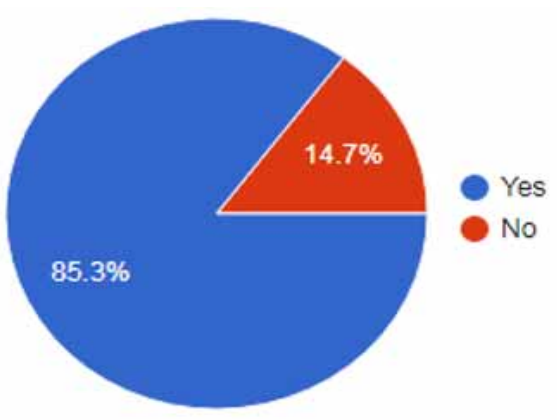

Figure 8: Lebanese women addictive to social media

\subsection{Teenagers are vulnerable to new ideas}

Jay Giedd, a child psychiatry researcher at the National Institute of Mental Health, says that the rapid changes occurring in the brains of teenagers make these years a time of enormous opportunity (Giedd, 2014). Teenage brains can be imprudent, as scientists reported at the Society for Neuroscience meeting in New Orleans, but also vulnerable, dynamic and highly responsive to feedback (Hamilton, 2012). Their brains are "wired" to engage in risky behaviour such as drug use or unsafe sex. These studies have concluded that teens are driving around with no steering wheel and no brake (Hamilton, 2012) and that ideas that teenagers are interpreting it are not the same as an adult since teens cannot think things through at the same level as an adult (Packard, 2007).

\subsection{People post their best photos}

Although we firmly believe that most of the people prefer to post their best photos on social media, we will try as much as possible to prove it in this section. We start by determining the most used social media platforms, in the world and Lebanon, then we list the primary use or purpose of each social media and finally relate both findings to determine the primary purpose for using social media. For example, if the most used social media platforms are Linkedln, and the primary use or purpose for using Linkedln is to advance in a career, then both findings conclude that the primary purpose for using social media is advance in career. In the end, we refer to the figure we extracted from our survey on females in Lebanon.

\subsubsection{Mostly used social media platforms}

According to the Pew Research Centre, the most used social media platforms by teenagers in the United States are Facebook, Instagram, and Snapchat as shown in Figure 9.

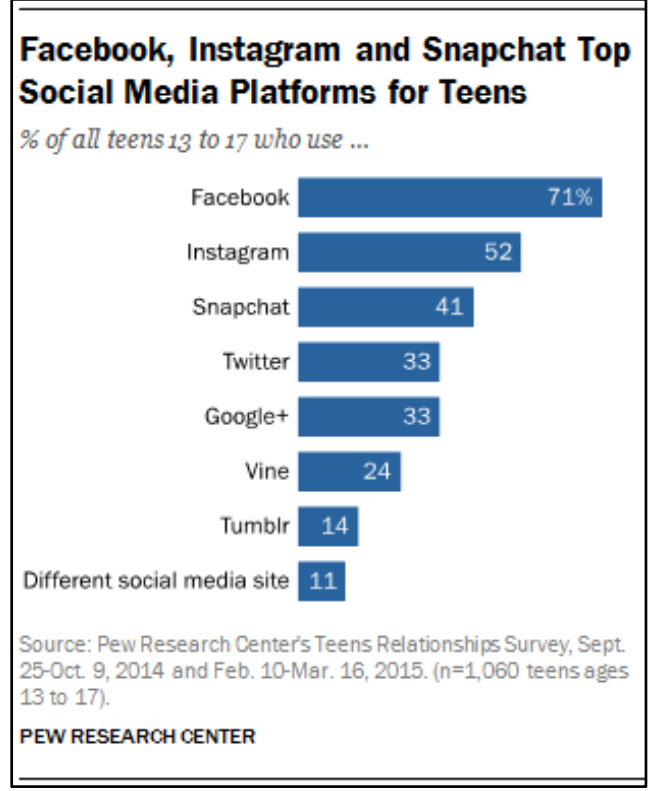

Figure 9: Social media platforms for teens

Facebook is the most popular and frequently used social media platform among teens (Lenhart, 2015). It has shown that $71 \%$ of the teens use it. Half of them use Instagram with a percentage of $52 \%$, and nearly as many use Snapchat with a percentage of $41 \%$. These three social media are mainly used to post photos and therefore to be more exposed to the public. For instance, in a 
different survey that Facebook conducted with Crowd DNA to interview and survey 13-24-yearolds who use Instagram from major marketers around the world (Roesler, 2019), nearly three out of four $(72 \%)$ said they posted images at least monthly; Instagram is mainly a place for people to share their lives with friends (Roesler, 2019).

\subsubsection{Facebook in Lebanon}

Facebook is the most popular and frequently used social media platform among Lebanese (Kemp, 2018) where almost two-thirds of the population use it as shown in Figure 10. It should be noted that there was a $+14 \%$ annual change in Facebook users from 2017 to 2018 which indicates that the users are increasing every year.

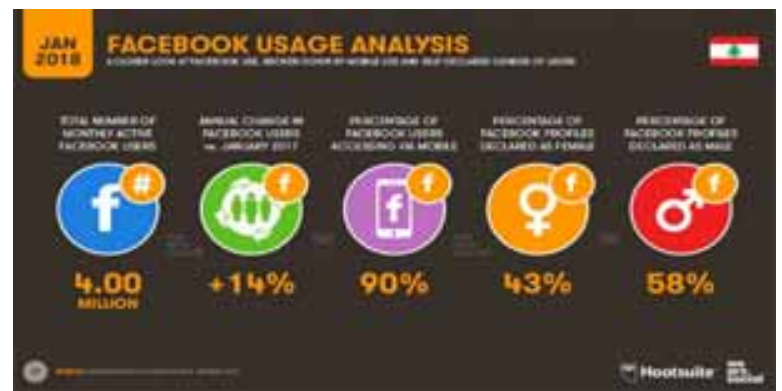

Figure 10: Facebook usage analysis in Lebanon

\subsubsection{Instagram in Lebanon}

On Instagram, the number of users is much less with $23 \%$ of the population as active users with almost equal distribution between male and female as shown in Figure 11.

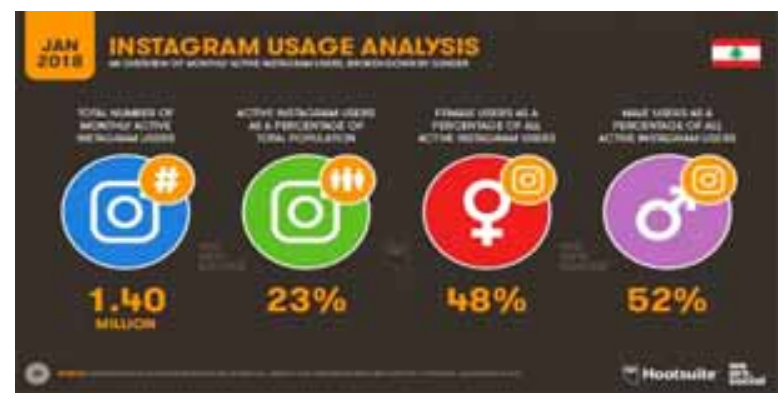

Figure 11: Instagram usage analysis in Lebanon

\subsubsection{Our survey}

The survey that we have done was on 100 users mostly single females. We found almost as to Pew Research Centre where most of the users use Facebook, and Instagram which is social Media mainly used to post photos as shown in Figure 12:

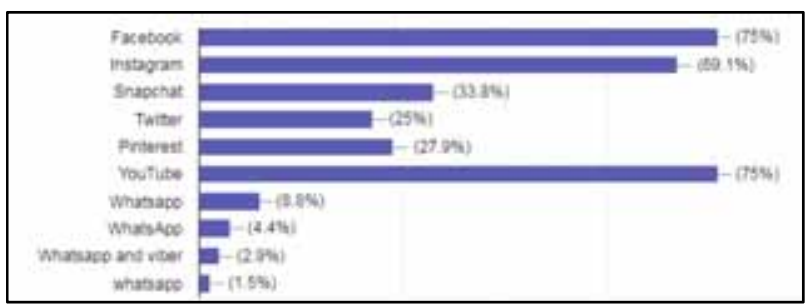

Figure 12: Facebook usage analysis in Lebanon
5.4.2. Primary use/purpose of each social media Twitter, Facebook, and Instagram are mainly used to increase the chances of communication between individuals (Bhasin, 2018). They mainly share personal details, comments, image, video posts, and a lot more. YouTube is one of the most popular and well-known sites that can be used for sharing media. Facebook, Linkedln, Twitter, Snapchat, Pinterest, and so forth. are also used for running paid ads? There are also blogs or websites that enable users to give their opinions and reviews in addition to primetime online games that are played on social media sites for entertainment

\subsubsection{The primary purpose for using social media}

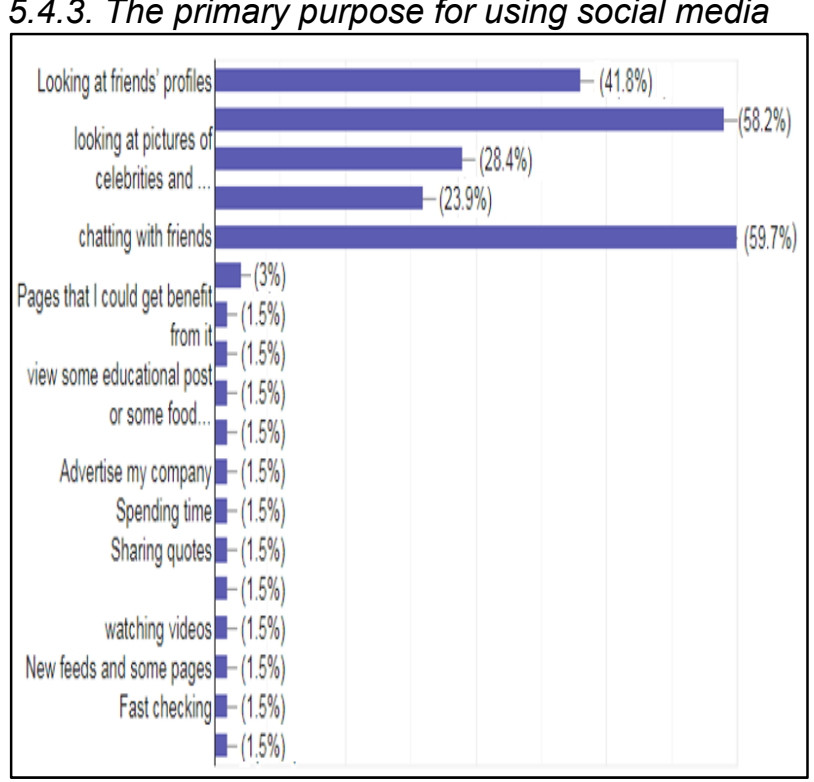

Figure 13: Most activities carried on Social media

We have shown in previous sections that the most used Social Media, in the world and Lebanon, are Facebook and Instagram. Then we have shown that the primary use or purpose of Facebook and Instagram is to share personal details, comments, image, video posts and other things. By relating both findings, we conclude that the primary use or purpose for using social media is sharing personal details, comments, image, video posts. This outcome demonstrates that most of the people tend to expose their photos to the public. With the availability of free photo correction software, such as RetouchMe, that can get the user a perfect face and body processing in few minutes without any photo editing skills, most of the people will post their best photos. To support this finding, the statistics we got from our survey shows that most of the users that are single-females look at pictures and profiles (Figure 13) and very often have their photos as the profile picture (Figure 14). 


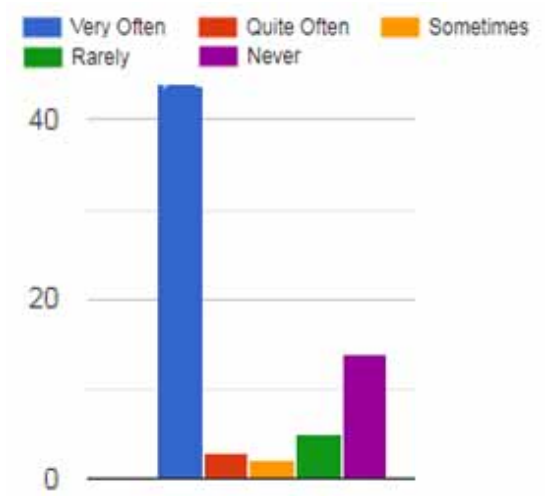

Figure 14: Having own photo as the profile picture

\subsubsection{Satisfaction with body image}

The Lebanese University conducted a study on students exposed to images of thin models and "perfectly shaped" famous figures (Richa, 2019). The study revealed that most of the students were dissatisfied with their bodies and showed changes in their eating behaviours leading to eating disorders; eating disorders describes illnesses that are characterized by irregular eating habits and severe distress or concern about body weight or shape (Ekern, 2018). From the survey we have conducted, we found that many of the respondents will go on a diet if they worry about their body shape as shown in Figure 15:

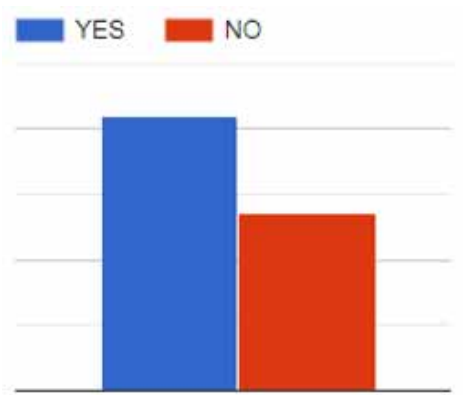

Figure 15: How many goes on diet

We also found from the survey that most Lebanese are not very often satisfied with themselves. Moreover, many think that they are not good at all, as shown in Figure 16.

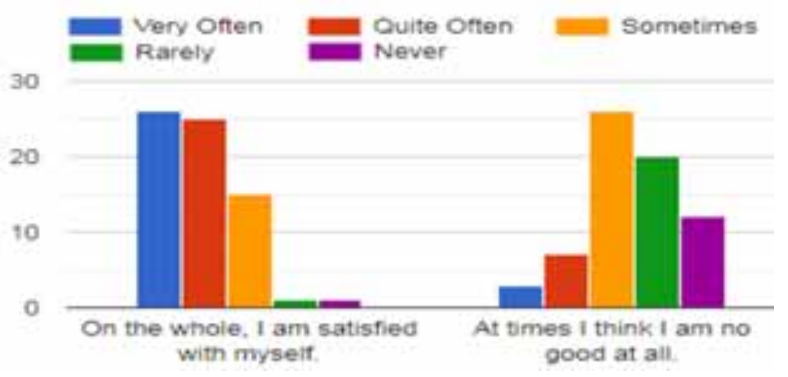

Figure 16: Satisfaction with body image

Adding this to the conclusion we got from the previous section, it becomes more evident that most of the people will post their best photos on social media.

\subsection{Teenage experiences affect adulthood}

\subsubsection{Development of traits in personalities}

Certain traits in our personalities are developed as a result of the experiences we pass through in life contrary to common beliefs that we inherit our personalities (Radwan, 2018). For example, identical twins who inherited almost the same genes have, in most cases, different personalities. Other studies showed that babies who received parental support were likely to have a better sense of security than their peers and kids with better academic results had better home environments than their friends (Michelle, 2017).

\subsubsection{Adults with childhood desires}

Radwan showed in (Radwan, 2018) that "a Person will try to fulfil his same childhood desires when he becomes an adult in a way that is acceptable by his society and culture". Also, children create an internal map of how the world is out of the events they witness and the things that happen to them (Brandt, 2017).

\section{SUMMARY AND CONCLUSION}

\subsection{Summary}

This paper uses a tree-like model of research questions and their possible outcomes, to investigate if beauty standards set by social media influence a teenager's body image. It also uses a survey that we have done for collecting data from a group of respondents to gain information and awareness on various topics of interest. We examine the research questions and for each one we identify a possible outcome. The expected result is to demonstrate that "Most teenage girls are influenced by social media and mainly on the beauty standards". After that, we examine if teenage experiences affect their adulthood. Combining the two findings, we can conclude whether or not beauty standards set by social media influence women's body image. The paper also covers social media platforms, research centres, and statistics' tools, photo editing software used on social media and an overview of child development.

\subsection{Conclusion}

We have shown in this paper that the primary use or purpose for using social media is sharing personal details, comments, image, video posts. This outcome demonstrates that most of the people tend to expose their photos to the public. We have backed up this outcome by statistics from agencies and from a survey that we have conducted on Lebanese mostly female and single. Then we have shown that most of the teenage girls use social media in Lebanon. With references to studies in the development of traits in personalities, that show 
how Teenage experiences influences adulthood, we have concluded that teenage girls are influenced by social media and mainly on beauty standards. Consequently, social media will affect their life when they become adults by following the beauty standards of social media

\subsection{Limitations}

We have expected to have fewer statistics on Lebanon regarding social media but it turns out that most of the research centres had many data on Lebanese people using social media.

The main limitation we had was the low number of respondents to the survey that we have sent online. We were expecting more than 200 respondents whereas we have received seventy

\subsection{Future Work}

In further research should be done on other countries in the Middle East with an emphasis on getting more responses to the survey to submit.

\section{REFERENCES}

Bhasin, H. (2018, November 06). What Are The Uses Of Social Media? Retrieved June 02, 2019, from social media marketing https://www.marketing91.com/what-are-theuses-of-social-media/

Brandt, A. (2017, June 01). 4 Ways That Childhood Trauma Impacts Adults. Retrieved June 03, 2019, from Psychology Today: https://www.psychologytoday.com/us/blog/mindf ul-anger/201706/4-ways-childhood-traumaimpacts-adults

Cara Booker, Y. K. (2018). Gender differences in the associations between age trends of social media interaction and well-being among 10-15 year olds in the UK. Volume 18(Number 1, Page 1).

Dakin, P. (2014, February 24). Social media affecting teens. Retrieved June 06, 2019, from Concepts of friendship, intimacy: http://www.cbc.ca/news/health/social-mediaaffecting-teens-concepts-of-friendship-intimacy1.2543158

Ekern, J. ( 2018, July 11). Eating Disorders: Causes, Symptoms, Signs \& Medical Complications. Retrieved June 02, 2019, from Eating Disorders Hope: https://www.eatingdisorderhope.com/information/ eating-disorder

Garst, Kim. (2019). Top 10 Social Media Statistics for 2019. Retrieved June 02, 2019, from https://kimgarst.com: https://kimgarst.com/socialmedia-statistics/
Giedd, J. (2014). Inside the Teen Brain. Retrieved June 2019, from Frontline: https://www.pbs.org/wgbh/pages/frontline/shows/ teenbrain/interviews/giedd.html

Hamilton, J. (2012, October 16). Teenage Brains Are Malleable And Vulnerable, Researchers Say. Retrieved June 03, 2019, from Health News From NPR: https://www.npr.org/sections/healthshots/2012/10/16/162997951/teenage-brainsare-malleable-and-vulnerable-researchers-say

Harrington, S. (2013). Hey you, it's all about me. 113(16).

Kemp, S. (2018). Digital In 2018: World's Internet Users Pass The 4 Billion Mark. New York: We Are Social.

Lenhart, A. (2015, April 09). Teens, Social Media \& Technology Overview 2015. Retrieved June 02, 2019, from Pew Internet: https://www.pewinternet.org/

Liu R-D, S. C.-X. (2013). Children's internet information seeking, life satisfaction, and loneliness: the mediating and moderating role of self-esteem. (68:21-8).

Mai-Ly Steers, R. W. (2014). Seeing Everyone Else's Highlight Reels: How Facebook Usage is Linked to Depressive Symptoms. Volume 33(No. 8, pp. 701-731.).

Michelle, L. (2017, August 27). 8 Early Childhood Experiences That Continue to Affect You Even in Adulthood. Retrieved June 03, 2019, from Learning Mind: https://www.learningmind.com/early-childhood-experiences/

O'Keeffe GS, C.-P. K. (2011). Clinical report - the impact of social media on children, adolescents, and families. (127(4):800-4).

Packard, E. (2007, April). Harvard researchers may have found biological clues to quirky adolescent behavior. Retrieved June 03, 2019, from That teenage https://www.apa.org/monitor/apr07/teenage

Radwan, M. (2018). Do childhood experiences affect adulthood. Retrieved June 2019, 03, from how childhood experiences affect adulthood: https://www.2knowmyself.com/how_childhood_e xperiences_affect_adulthood

Richa, N. (2019, March 11). Social Media and Eating Disorders in Lebanon. Retrieved June 03, 2019, from Life \& Entertainment Health: https://en.annahar.com/article/946480-socialmedia-and-eating-disorders-in-lebanon

Roesler, P. (2019). Study Shows Why Teens And Young Adults Love Instagram. Jacksonville: Web Marketing Pros. 
Sameer, M. (2014, November 20). Impact Of Social Networking Sites On Youth. Retrieved June 06, 2019 , from http://www.youthkiawaaz.com/2011/06/socialnetworking-impact-youth/

Santos R, M. J.-E.-S. (2014). The independent associations of sedentary behaviour and physcial activity on cardiorespiratory fitness. (48:1508-12).

Zhukova, A. (2018, October 31). 7 Negative Effects of Social Media on People and Users. Retrieved June 06, 2019, from Social Media: https://www.makeuseof.com/tag/negativeeffects-social-media/ 